\title{
The End of the World and Architecture
}

Michael A. Richards

michael.a.richards@uvm.edu 


\title{
The End of the World and Architecture
}

\author{
Michael A. Richards
}

\begin{abstract}
Sustainability is defined as meeting our current needs without compromising the needs of future generations. The question remains, however, how far into the future must we plan for? Our universe is almost 14 billion years in age, and scientists predict that it will live on at least another 14 billion years, whereby it will approach finality in either a "Big Crunch" singularity, or continue expanding until it becomes complete darkness - "The Big Chill”. Sustainability, therefore, becomes a relative concept - even before our universe ceases to exist. From cosmic supernovas, black holes, and collisions with asteroids to earth-bound disasters such as nuclear holocaust, natural resource depletion, and biological/genetically engineered pathogens, humanity is indeed in danger of becoming extinct. Maybe our fate is inevitable and such events are simply too large for us to comprehend, and simply are "out of sight and out of mind." Or maybe thinking on such a grand scale will make the more imminent dangers our planet faces seem more solvable. In examining disasters of such magnitude, it will become imperative for architecture to transform its pedagogy and expand its expertise in order to provide sustainable solutions that will preserve humanity's existence.

In recent times, there has been a focused concentration on designing green buildings and utilizing renewable sources of energy - all of which are in some way derived from the sun. This paper takes this a step further and asks, what will happen when there is no sun? What will happen when all of resources that we rely on to live are depleted? Although these events may be millions or even billions of years away, should we be concerned with them now? In order to truly engage sustainability, we must examine not just the "immediate" future, but also the "distant” and "very distant” future.
\end{abstract}

\section{The Disasters}

This paper will discuss several types of cataclysmic disasters humanity will face in the distant future that will threaten our very existence. The disasters range from cosmic events such as the death of the sun, cosmic collisions, and black holes to Earth bound events such as a nuclear holocaust, biological/genetically engineered pandemics, and natural resource depletion. The Lifeboat Foundation $(2010$, a.) defines these disasters as existential risks - risks that are global and terminal that would either annihilate Earth-originating intelligent life or permanently and drastically curtail its potential. Although the emphasis of this paper is on such existential disasters, some of the design solutions can also be applied to and/or create novel solutions for some of the more common natural disasters such as earthquakes, tornadoes, tsunamis and floods. 


\section{The Death of the Sun}

Our sun is classified as a yellow dwarf of medium size (864,000 miles in diameter) and of medium age (about 5 billion years old). The sun is a giant nuclear furnace that fuses hydrogen into helium at a temperature of 27 million degrees Fahrenheit and yields some 400 trillion watts of energy that provides life on Earth. (Astronomy Encyclopedia, 2002) The sun will remain stable as long as the energy from the nuclear reactions is sufficient to balance its gravitational attraction. Scientists predict our sun will burn for another 5 billion years or so. At this point, the hydrogen will become depleted at the core, ultimately ceasing thermonuclear reactions between the hydrogen and helium. The core will increase in mass and begin to collapse upon itself. The collapse will continue to heat up the remaining hydrogen outside the core that will cause the sun to burn hotter and brighter. As the core becomes hotter, it will start to convert helium into heavier elements such as carbon and oxygen. The energy exuded from the collapse will cause an energy release that will inflate our sun into a red giant that will vaporize the inner planets of our solar system. Once all the energy is exhumed, the central regions of the star will collapse into a white dwarf.

Even before the sun actually burns out, the aging process will begin to drastically change the climate on Earth. The first noticeable changes will be the melting of polar ice caps that will in turn cause sea levels to rise and diminish Earth's ability to cool itself. Over time, the planet will continue to warm until the oceans evaporate, the surface is blazed, and the entire planet is vaporized by the inferno of the bloated red giant. Although this event is some 5 billion years away, we are starting to see signs of global warming from both human induced and natural processes as we speak. Conditions may become intolerable within thousands of years and even inhabitable as soon as millions of years.

When larger stars collapse, the outer regions get expelled into space in a massive explosion known as a supernova. Supernovas occur on average about once a century in any particular galaxy. The last one recorded in the Milky Way was in 1604 and was about 25,000 light years away from Earth. (Dickinson, 1992) The highest probability for a supernova in the Milky Way is a star called Rho Cassiopeiae, which has been decaying since 1946 and had a major eruption in 2000. (Astronomy Encyclopedia, 2002) Although this star is 10,000 light years away and most likely would not impact our solar system, gamma radiation and shock waves from supernovas less than 1000 light years away could alter and/or damage the molecules that make up living organisms. There are currently no contenders in this range, but the universe is unstable. There are also other doomsday scenarios in the Apocalypse 2012 theories that start with a solar flare from the sun that heats up Earth's crust thereby causing super-volcanoes that blanket the Earth in ash, earthquakes that swallow continents, and tidal waves/tsunamis that wash away coastal cities.

The question for architects, engineers and designers remains: Should we even be concerned with cataclysmic sun/Earth-annihilation scenarios? Since there is really no way to save the planet from this fate, and no urgency since this destruction is some 5 billion years away, is it even worth planning for? Maybe such fate is too immense for us to cope with. But then again, maybe thinking and planning on such a grand scale can yield new ways of addressing the more imminent dangers our planet faces. One thing scientists know for sure is that the universe is 
unpredictable. Global mass destruction could happen tomorrow, 1000 years from now, or 5 billion years from now, and that there is no better time than the present to start planning and designing for the worst case scenarios.

\section{Cosmic Collision}

Anyone who has watched science fiction films such as Armageddon, Deep Impact, or 2012 might be dismally aware of the threat Earth faces from a catastrophic impact from matter in space. Such matter could be in the form of asteroids, meteoroids, or comets. Asteroids are essentially miniature planets that range in size anywhere from 10 meters ( 30 feet) in diameter to the largest known asteroid, Ceres, which is $933 \mathrm{~km}$ (580 miles) in diameter. (Astronomy Encyclopedia, 2002) Most of the known asteroids orbit the sun in a zone between Mars and Jupiter. "The prevailing theory is that Jupiter's gravitational influence so perturbed this region of solar nebula that one large planet was never able to develop. Instead, a number of smaller ones did, and later fragments continued colliding." (Dickinson, 1992, p.64) Particles smaller than 30 feet (10 meters) in diameter are usually classified as meteoroids, and comets are masses of ice with mineral deposits that originate from beyond the limits of our Solar System in a region known as the Oort cloud.

Although it is estimated that there are some 19,000 meteorites over 100 grams that hit the Earth annually, large asteroids with diameters greater than a mile that reach the Earth occur only about once every 100,000-300,000 years or so. Evidence suggests that an asteroid roughly 12 miles $(19 \mathrm{~km})$ in diameter crashed into the Earth and was responsible for the extinction of the dinosaurs some 65 million years ago. The asteroid is thought to have been traveling roughly 62,000 miles per hour and left a 125-mile ( 200 km) diameter crater in the area now occupied by the Caribbean Sea. (Dixon, 1997)

Research of the Cretaceous meteorite has lead scientists to become increasingly concerned about the possibility of another such event occurring in our lifetime. In 1998, NASA established the Near Earth Object Program (NEOP) to monitor and study objects approaching the Earth's orbit.

Near Earth objects are asteroids, comets or meteoroids with a perihelion distance less than 1.3 AU. As of May 4, 2010, 6997 Near-Earth Objects have been discovered, 810 of these with diameters larger than $1 \mathrm{~km}$, and 1110 of these classified as Potentially Hazardous Asteroids (PHA's). PHAs are defined as asteroids larger than 500 feet in diameter that have minimal orbit intersection distances less than .05 AU (4,655,000 miles). (Near Earth Object Program, 2010, a.)

Overall, when accounting for asteroids that are not considered Near Earth Objects (perihelion distances greater than $1.3 \mathrm{AU}$ ), there are probably about 100,000 with a diameter greater than $305 \mathrm{ft}$ ( 93 meters), and 150 million with a diameter greater than $30.5 \mathrm{ft}(\sim 9$ meters). (Dixon, 1997). To assess impact risk, the NEOP uses the Torino Scale, which is designed for communication with the public, and the more technical Palmero Scale for more inhouse, proprietary calculations. The Torino Scale ranges from 0 to 10 , zero being no hazard, and 10 being certain collision capable of causing global climatic catastrophe. As of May 5 2010, the top three asteroid contenders for potential impact with Earth are 1019551999 RQ36, 2007 VK184, and 999422004 MN4 (Apophis), with earliest impacts occurring in 2069, 2048, and 2036 respectively. (NASA, Near Earth Object Program, 2010. b) Granted, all of these are either a 0 or 1 on the Torino Scale and have Earth-striking probabilities of essentially zero. However, many scientists and theoreticians believe that "essentially" zero in not really zero and never 
underestimate the randomness and unpredictability of the universe. If an asteroid led to mass extinction once, it could happen again. So what if NASA's Near Earth Object Program discovered a highly probable impact tomorrow that would potentially strike the Earth in a 10-20 year window, what would be our plan? Is technology in place to target such an asteroid with missiles and/or lasers that could destroy it? What if it is too large to destroy? What if we make contact with arsenal but small amounts of debris and radiation still impact the Earth? If defensive and/or offensive technology fails, back-up plans from architects and engineers will be the only hope in sustaining human life.

In addition to asteroid, comet and meteoroid collisions, there are also possibilities of collision with other galaxy's and the consumption by black holes resulting from other dying stars in our galaxy. Scientists predict our galaxy, The Milky Way, will collide with Andromeda Galaxy in the distant future:

At the moment, Andromeda is about 2.2 million light years away from us but the gap is closing at 500,000 $\mathrm{km} /$ hour. While most galaxies are rushing away as the universe expands, Andromeda is the only big spiral galaxy moving towards the Milky Way. The best explanation is that the two galaxies are in fact a bound pair in orbit around one another. Both galaxies formed close to each other shortly after the Big Bang initially moving apart with the overall expansion of the universe. But since they are bound to one another, they are now falling back together and one very plausible scenario puts them on a collision course in 3 billion years." (Dubinski, 2006)

The merger could present a myriad of opportunities for other forms of destruction, but also might present new opportunities for actually sustaining life. For example, assuming we survive billions of supernovas, star implosions, and galactic matter collisions, we might find new planets and stars that we could exploit for resources and habitation. Galactic merging also makes interstellar space travel more attainable. At current rates of movement, Andromeda might be reachable by spacecraft technology many millions of years before it actually collides with the Milky Way.

\section{War, Terrorism, \& Nuclear Holocaust}

With discussion of external cosmic forces with capabilities of ending life as we know it, it is disheartening to think that humans would ever try to destroy each other. Who knows, maybe the threat of a moon-sized asteroid colliding with Earth might actually get humanity to work together...but as history has demonstrated, this is doubtful. As humans, we have some defective destiny to destroy ourselves and will probably do so long before the sun dies, an asteroid hits us, or we collide with Andromeda. It is a grim, but sadly true prophesy. When accounting for just the major wars that the United States has been involved with throughout history, there have been roughly 2,604,824 casualties (deaths and wounds) within our armed forces. (World Almanac, 2010) In his Historical Atlas of the $20^{\text {th }}$ Century (2010), Matthew White estimates about $188,000,000$ worldwide deaths by war and oppression in the $20^{\text {th }}$ Century. This includes genocide and tyranny, military and civilian deaths in war, and human induced famine. Somewhere in our universe, or in some other universe, more advanced civilizations are laughing at us; "Look at those primitive species with their guns, wars, drugs, greed, and tyranny; what a bunch of savages... when will they ever learn how to peacefully coexist?" 
As technology becomes more sophisticated, wars become more dangerous and the potential for mass destruction increases. New arsenals of nuclear weapons, biologically engineered diseases (see below), cyber-terrorism, and other forms of advanced weaponry increasingly threaten our existence - especially if they get into the wrong hands.

The harsh reality is that we will never learn to peacefully coexist. There will always be factions of extremists that threaten the world and human differences in race, religion, politics and lifestyle that will most likely never find harmony. If we transformed all the energy we spent fighting each other to actually working together, we probably could solve the world's energy crisis, cure disease, and actually have safeguards in place in response to the some of the disasters discussed in this paper.

\section{Biological Pandemics}

It was difficult to ignore the threat of pandemics with the fury generated from the H1N1 Flu Virus that spread the globe in 2009. An epidemic is defined as an outbreak of a communicable disease that affects a significant amount of people in a specific region at the same time; a pandemic is an epidemic on a global scale. (CDC, 2010) There have been several pandemics throughout history, including measles, small pox, Bubonic Plague, syphilis, yellow fever, cholera, poliomyelitis, and the Spanish Influenza of 1918 that killed 20 million people worldwide. Although many of these diseases are treatable and curable in modern times, there are still diseases that evade medical technology and there will always be new pathogens that evolve. As of 2010, there are roughly 33,000,000 people living with HIV/AIDS worldwide, and since its discovery in the early 1980's, there have been 2,000,000 deaths from AIDS and/or HIV/AIDS related infections. (World Almanac, 2010). According to the Lifeboat Foundation (2010, b.):

Today more than a quarter of all deaths worldwide -15 million each year - are due to infectious diseases. These include 4 million from respiratory infections, 3 million from HIV/AIDS, and 2 million from waterborne diseases such as cholera. This is a continuing and intolerable holocaust that, while sparing no class, strikes hardest at the weak, the impoverished, and the young.

In addition to pathogens that are evolving naturally, there is now also the imminent threat of human engineered pathogens. According to the Centers for Disease Control and Prevention (2010):

A bioterrorism attack is the deliberate release of viruses, bacteria, or other germs (agents) used to cause illness or death in people, animals, or plants. These agents are typically found in nature, but it is possible that they could be changed to increase their ability to cause disease, make them resistant to current medicines, or to increase their ability to be spread into the environment. Biological agents can be spread through the air, through water, or in food. Terrorists may use biological agents because they can be extremely difficult to detect and do not cause illness for several hours to several days. Some bioterrorism agents, like the smallpox virus, can be spread from person to person and some, like anthrax, can not.

\section{Depletion of Natural Resources}

In addition to the destruction of our planet from the forces mentioned above, humans should also be aware that our resource consumption is rapidly exceeding resource availability. The world's population is currently about 6.4 billion. Although some of the more developed countries are 
starting to taper in terms of population growth, much of the developing world is still expanding at exponential rates. In fact, over 95\% of population growth is in the developing world. (Worldwatch Institute, 2006). As the human footprint increases, strain on our resources increases. It is quite possible some time in this century that the population rate will exceed food supply, energy sources, and land area for habitation, agriculture and waste disposal. According to Professor Charles H.V. Ebert (1993):

Human's relationship with the ecosphere proceeds along a J-curve; that is to say that at first humankind was an integral part of the living world, existing in harmony with the total system, and did not exert any excessive influence. But over time, humans assumed a different role and attained the position of changing the environment consciously, not instinctively.

According to the National Resources Inventory, about 8900 square kilometers (2.2 million acres) of land was developed between 1992 and 2002 in the United States. (USDOA, NRI 2009. http://www.nrcs.usda.gov) In their book, Designing Greenways: Sustainable Landscapes for Nature and People (2006), Paul Hellmund and Daniel Smith state:

Likewise, the capitalist economy that has helped to produce a remarkable high standard of living for a minority of the world's inhabitants relies on the constant dissolution and reconstitution of nature and society into new forms. Economists aptly refer to this as "creative destruction" and it is, for better or worse, the lifeblood of our economy. (Preface, xi)

In addition to urban and suburban development, soils and forests are also being degraded by clear cutting, overgrazing, and agricultural mismanagement. As the surface of the Earth becomes increasingly impermeable, the hydrological cycle is interrupted by the increase of water runoff and a decrease in infiltration and groundwater recharge. As a result, streams and water bodies become polluted and are subject to extreme flooding during wet cycles and severe drought during dry cycles. As groundwater is leached, land actually settles or "sinks" - an occurrence known as land subsidence. "Asphalt and concrete rooftops, roads and parking lots cover up to $70 \%$ of land area in dense cities like New York, while open space in sprawling cities such as Phoenix, Arizona is lost to development at a rate of 1.2 acres per hour.” (Earth Pledge \& ScholzBarth, 2005, p.16)

Since the Industrial Revolution, fossil fuels have been exploited to provide energy to the world. According to the Worldwatch Institute (2006), roughly 80 percent of the world's energy comes from oil, coal, and gas. The International Energy Agency estimates that oil demand reached 3.8 million tons in 2005, or 83.3 million barrels a day. Coal reached nearly 2.8 million tons and natural gas roughly 2.4 million tons in 2004. So how long will these reserves last? It depends who you ask, of-course. There are also factors such as "estimated" reserves versus "proven" reserves, and within the proven reserve category, the probability can range from 0 to 100. Data from agencies such as the US Department of Energy and the USGS estimate that there are anywhere from 1,020 to 1,420 BBs of proven and unproven oil remaining in the Earth. (Wright \& Nebel, 2002) Anyone can do the math. If the world is using 83.3 million barrels of oil per day or roughly 30 billion barrels per year, and there is an optimistic estimate of 1420 billion barrels left, we have roughly 47 years of oil remaining. Remember, this is the most optimistic estimate. This assumes oil usage stays the same and that the oil actually exists and is retrievable in the "unproven" reserves. Not surprisingly, the US is the world's largest consumer of oil, using roughly 20.8 million barrels a day. (Worldwatch Institute, 2006) One thing experts are sure of is that we will definitely run out of Earth derived crude oil sometime in the 21st Century, and that radical shifts in our fuel economy must be achieved. 
A conversion to renewable sources of energy (assuming the sun is still healthy) and aggressive planning approaches to conserve land are imperative. The problem is that human population continues to grow, so where do you put all these people? How much land is required to harvest enough food for such projected population growth? If we run out of fossil fuels, will renewables yield enough energy for future populations? How do you control population growth without infringing on human's freedom? Can we design new worlds in outerspace, colonize other planets and explore the depths of our oceans that will protect us from cosmic collisions, pandemic viruses, nuclear holocaust and natural resource depletion? The next section of this paper will examine potential design solutions that could potentially provide relief from the epoch disasters discussed above.

\section{Colonizing Space}

The colonization of space represents the most sustainable design solution to a majority of the catastrophic disasters discussed above since it creates a new world physically separated from Earth-bound perils and could forge the possibility of relocating to another star in the event that our sun decays. There are three major strategies in colonizing space that each rely on their degree of advancement in technology: orbiting space colonies, the terra-formation of other planets, moons, or asteroids, and interstellar space travel.

Since the times of the great space race in the mid $20^{\text {th }}$ Century, there have been significant advances in the exploration of space. In 1926, Robert H. Goddard launched the first liquid fueled rocket. It only reached a height of 41 feet $(66 \mathrm{~km})$, but was soon followed by the first suborbital flight (reaching 62 miles/100 km) of the German V2 rocket. The Russians were the first to put a human in space in 1961, and the United States' Apollo 11 mission was the first to land on the moon in 1969. The 1970's saw a surge in sending probes into outerspace, including the Soviet's Venera 7 landing on Venus in 1970, the US's Viking 1 and Viking 2 landing on Mars in 1976, and the Voyager 1 and 2 missions that orbited Jupiter in 1979, Saturn in 1980, Uranus in 1986 and Neptune in 1989... and these are just a few. The first space shuttle, STS-1 Columbia, was launched in 1981, and as of October 2009, there have been 128 space shuttle flights. (World Almanac, 2010). Other notable advancements include The Near Earth Asteroid Rendezvous (NEAR) landing on the Eros Asteroid in 2001, the Spirit \& Opportunity rovers landing on Mars in 2004, and the Cassini Probe arriving at Saturn in 2004.

In addition to flight advancement, there also has been significant progress in the aerospace engineering of space structures. The Soviet Salyut 1 became the first human-occupied orbital space station in 1971. This was followed by the United States Skylab in 1973, the Russian Mir Station in 1986, and the International Space Station (ISS) in 1998. The ISS is an international joint project between the National Aeornautics and Space Administration (NASA), the European Space Agency (ESA), the Russian Federal Space Agency (RKA), the Japanese Aeospace Exploration Agency (JAXA), and the Canadian Space Agency (CSA). According to Boeing (2010):

The first module - the Russian Zayra - was launched in 1998, and currently, there have been 88 space missions that have assembled about 13 interconnected modules powered by 20 solar arrays generating 80-120 kilowatts of power. NASA is committed to completing the ISS in 2010. When completed, it will measure 356 feet (109 meters) from port to starboard, equivalent to the length of a football field, have an internal 
pressurized volume of 34,700 cubic feet, weigh almost one million pounds (453, $592 \mathrm{~kg}$ ), and will maintain an average altitude of 220 miles ( $354 \mathrm{~km}$ ).

The station's primary use is for research in the human exploration of space, monitoring meteorological and climatic patterns of the Earth, and studying human and plant biology in a microgravity environment. The ISS may pave the way for larger space colonies in the near future. NASA'a Ames Research Center actually conducted studies for such larger colonies in the 1970's. The colonies were designed to house 10,000 people and consisted of Toroidal, Cylindrical and Bernal Sphere designs. All of these designs employ air tight atmospheres rich in oxygen and nitrogen and employ rotational effects to simulate gravity. According to NASA (2010):

As an orbital space colony turns, the inside of the colony pushes on the inhabitants forcing them to go around. The amount of this force can be controlled and for reasonable colony sizes and rotation rates the force can be about 1g. For example, a colony with an 895-meter (a bit less than 1000 yards) radius rotating at one rpm (rotations per minute) provides $1 \mathrm{~g}$ at the hull.

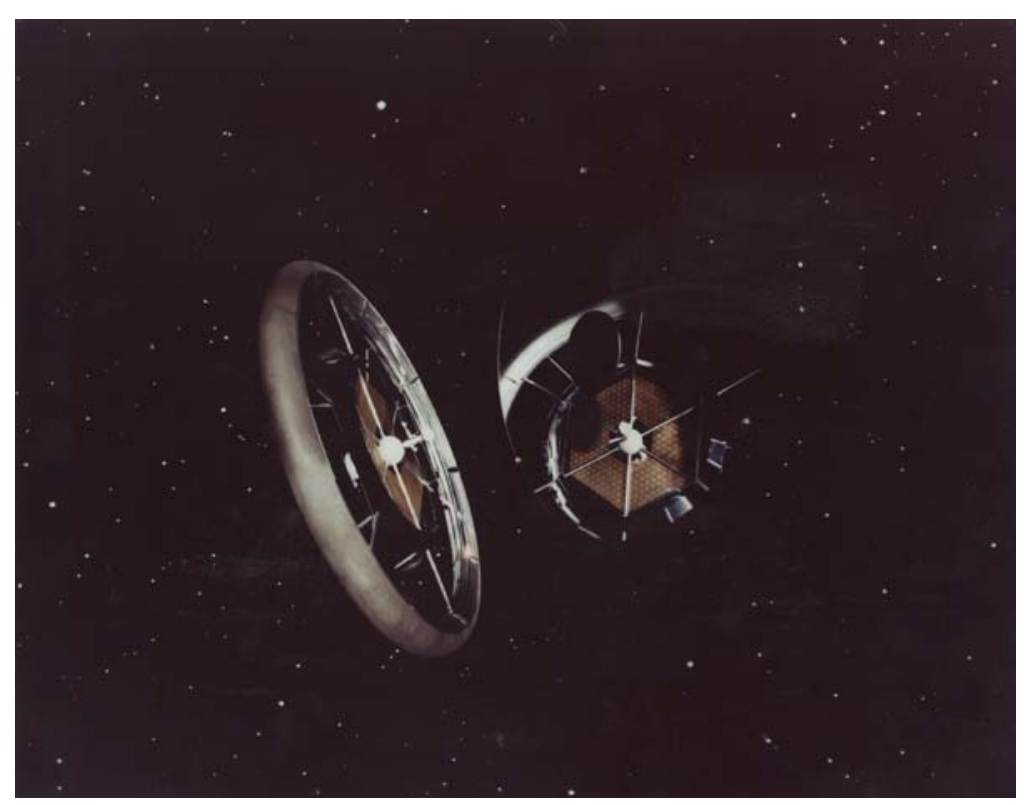

Figure 1: Toroidal Space Colony, Exterior View. Courtesy: NASA, Ames Research Center 


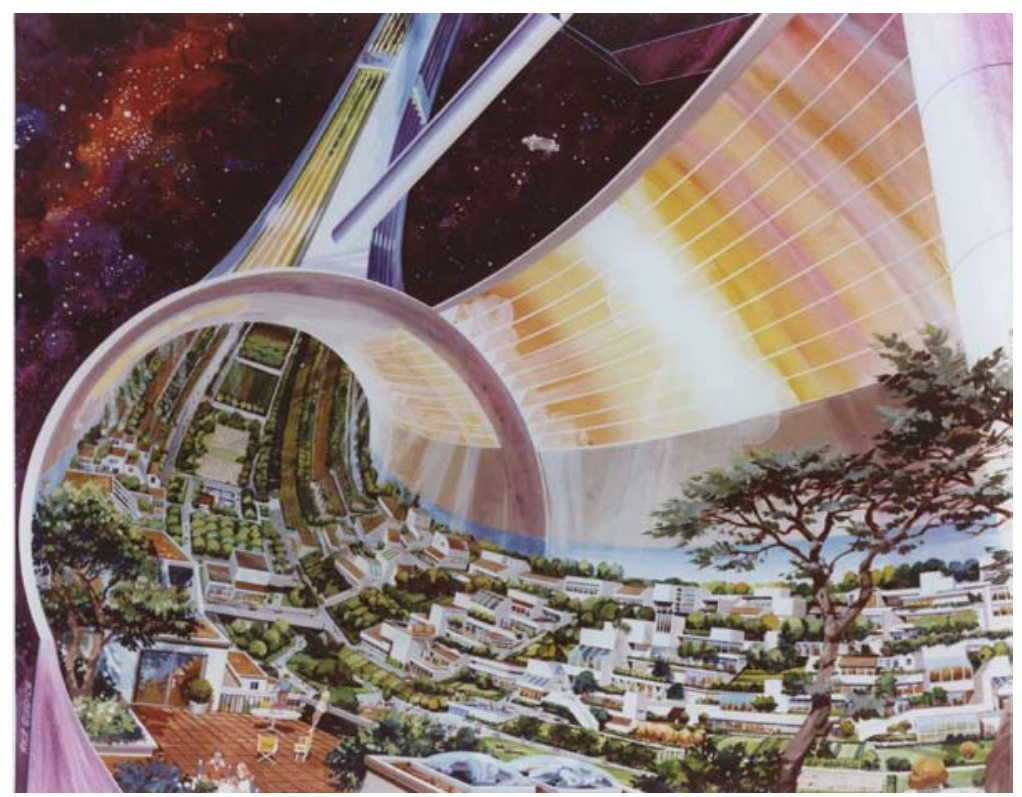

Figure 2: Toroidal Space Colony, Interior View. Courtesy: NASA, Ames Research Center

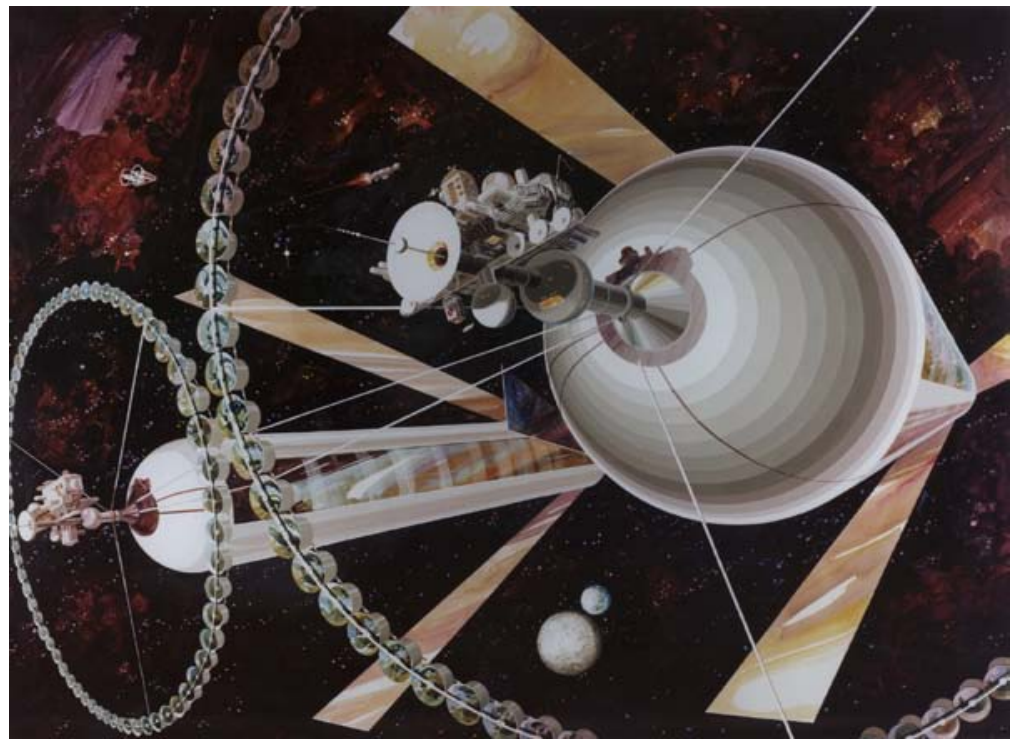

Figure 3: Cylindrical Space Colony, Courtesy: NASA, Ames Research Center 


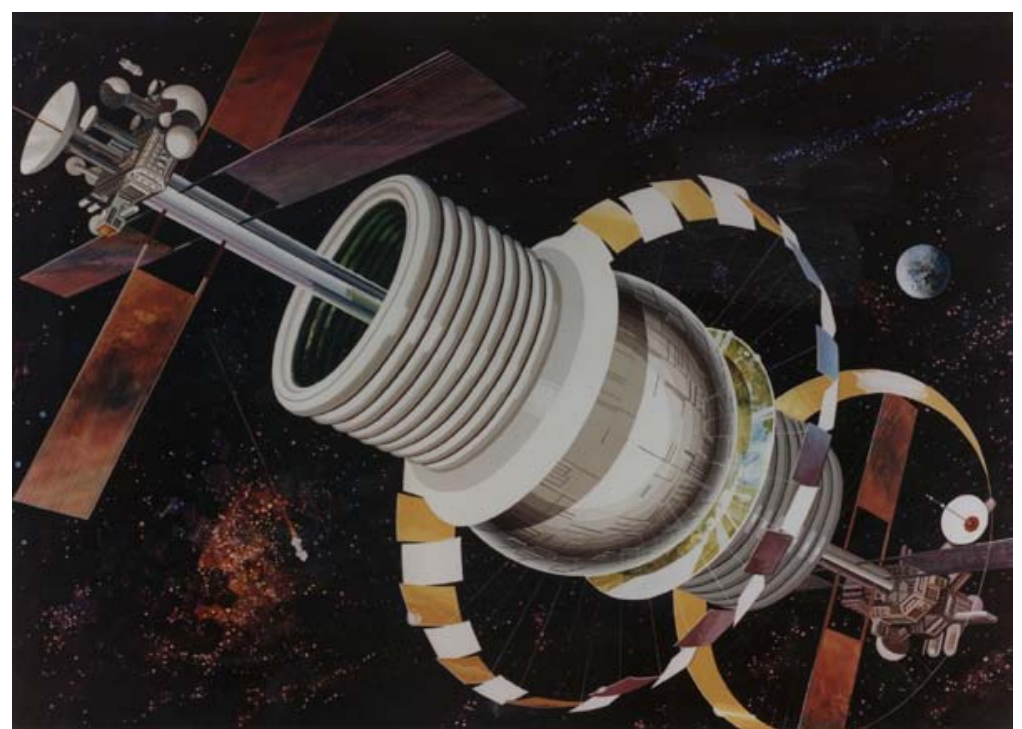

Figure 4: Bernal Sphere Space Colony, Courtesy: NASA, Ames Research Center

Although a majority of space craft and laboratories are currently designed primarily by aerospace and aeronautical engineers, future, more complex colonies will have to employ architects to design and program space, study light patterns, plan communities, and develop and monitor human-space interaction patterns. Dr. Gary Scott Danford of the University at Buffalo, The State University of New York, summarized the following requirements in a 1994 academic project description:

More specifically, architects, along with various other professions, will be challenged with the demographic and professional make-up of the colony and its means of selection, notification and segregation from the general population; the design of a viable physical environmental system that will be capable of sustaining human life in space in an active, conscious and productive state for extended periods; the programming of a stable system for social organization of the population that will not only provide for their safety and security, but also ensure the maintenance of their normal psychological and physiological development and well being; and designing an implementation plan for the safe transport of people to and from the Earth and the Space Colony.

Other issues the design must address are power generation, protection from radiation, solar flares/cosmic rays, methods to recycle resources and wastes, and safe, efficient technologies of transporting people to the colonies. In 2004, the first private space craft - SpaceShipOne, was developed by Scaled Composites. SpaceShipTwo is currently in development and the leading candidate for commercial space travel. The following description is from Scaled Composites (2010):

SpaceShipOne is a three-place, high-altitude research rocket, designed for sub-orbital flights to $100 \mathrm{~km}$ altitude. The unique configuration allows aircraft-like qualities for boost, glide, and landing. The ship converts (via pneumatic-actuated feather) to a stable, high-drag shape for atmospheric entry. This "care-free" configuration allows a "hands-off" re-entry and greatly reduces aero/thermal loads. Designed for a "shirtsleeve" environment, the 60 " diameter cabin has a space-qualified ECS, as well as dual-pane windows. The ship uses three flight control systems - manual-subsonic, electric-supersonic and cold-gas RCS. SpaceShipOne's hybrid rocket motor is a non-toxic, liquid nitrous-oxide/rubber-fuel hybrid propulsion system. The avionics onboard provide the pilot with the precise guidance information needed to manually fly 
SpaceShipOne for boost and re-entry. It also provides guidance for approach and landing and vehicle health monitoring. The unit stores and telemeters flight test data to Mission Control.

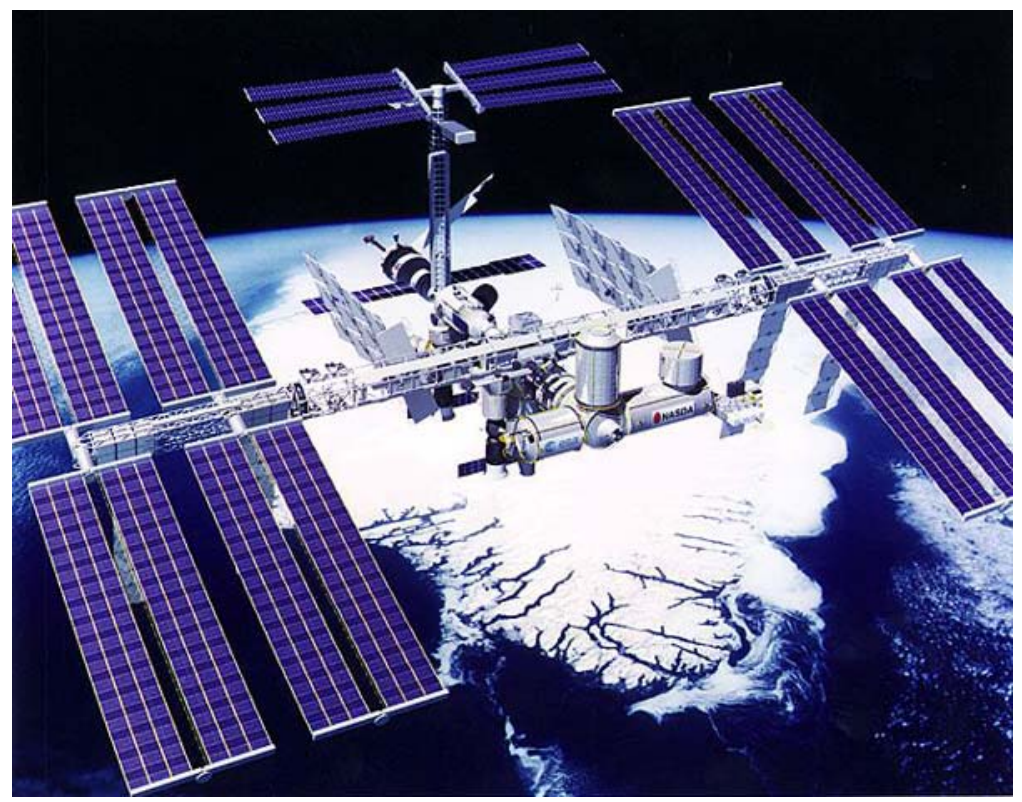

Figure 5: International Space Station, Courtesy: NASA Illustration via Boeing

Space colonies can provide a means of sustaining human life due to disasters on Earth from a cosmic collision, a lethal pandemic, or a nuclear holocaust, and even could provide some relief to the planet in terms of land conservation and resource consumption. It is also quite possible for space colonies to harness energy from the sun and transmit it to Earth via microwave beams. The only scenario an orbiting space colony would not provide protection against is the death of the sun. In this case, the colony would have to either self-propell or provide a series of "lifeboats" in the form of interstellar cruisers to relocate the civilization to a new star.

\section{Colonizing Other Planets}

Colonizing other planets, moons, and asteroids also presents significant design challenges for architects and engineers. Unlike an orbiting space colony, there really is no way (unless scientists discover gravitons) to simulate Earth-normal gravity of $1 \mathrm{~g}$. "The lunar surface is at roughly 1/6g and Mars is at 1/3g of Earth. Children growing up in such conditions would not be able to develop bones and muscles strong enough to return to Earth, and adults would suffer from a weakening of muscle and bone mass." (NASA, 2010) Similar to orbiting colonies, planets would also have to be either terra-formed or self-contained biospheres would have to be constructed to provide an Earth-like atmosphere. In their book, Islands in the Sky (1996), Schmidt and Zubrin describe this terra-formation process:

The essence of the condition is that while Mars' $\mathrm{CO}_{2}$ atmosphere has only about $1 \%$ the pressure of the Earth's at sea level, it is believed that there are reserves of $\mathrm{CO}_{2}$ frozen in the south polar cap and adsorbed within the soil sufficient to thicken the atmosphere to the point where its pressure would be about $30 \%$ that of Earth. In 
order to extract this $\mathrm{CO}_{2}$, the atmosphere would have to be warmed by either pumping artificial greenhouse gases into the atmosphere, angling orbiting mirrors that reflect sunlight at the planet, or by importing ammonia or methane to Mars via asteroids.

Once the planet is warmed, reservoirs of water deep in the crust would have to be released to activate a hydrological cycle, which would in turn release carbon dioxide and water vapor. This would then yield bodies of water, microorganisms, and the subsequent creation of plants, oxygen and hydrogen. The other possibility is that Mars will eventually warm on its own as the sun continues to expand. In this scenario, it is possible that space colonies orbiting Earth migrate to Mars with the eventual habitation of the red planet.

\section{Biospheres}

Until the natural or induced warming of Mars occurs, a colony of bio-domes could be designed on the surface of the planet. Self-contained environments such as Biosphere II in Arizona have been built to test how different environments react in a closed system. Biosphere II is a 3.14 Acre structure that was built between 1987 and 1991. The Biosphere contains five biomes, including an ocean with a coral reef, mangrove wetlands, a tropical rainforest, a Savannah grassland, and a fog dessert. Two missions were conducted between 1991 and 1994 . Eight people lived in the structure for the first mission. After about one year, the biosphere became deprived of oxygen. Luckily, since this was an experiment conducted on Earth, all scientists had to do was open the door to replenish the oxygen. But this would be a different story on another planet or moon. If the colony was built on our moon and oxygen became scarce, it might be easier to bail-out and get back to Earth, seeing the Earth-Moon distance is only 238,000 miles compared to the 36-250 million mile distance range between Earth and Mars.

Biosphere-like colonies constructed on Earth could, however, provide protective shelter against radiation from a cosmic collision or from nuclear bombs, and also could provide a sealed environment shielding humans from an Earth-bound biological pandemic. However, if oxygen levels are finite in such structures, they could only be used as temporary fallout shelters to these threats. This might be feasible if contamination levels on Earth after such events would diminish or even cease over time, allowing humans to repopulate the Earth.

Self-sustainable biosphere architecture could possibly become the norm in the near future. If all new structures built from this point forward were designed to generate their own power from renewable sources and/or grow their own food, significant reductions could be achieved in the use of non-renewable energy sources and in the amount of carbon released in the atmosphere. In addition, using structures to generate power provides alternative sites for large-scale energy operations that might otherwise consume large areas of land.

\section{Underwater Colonies}

Anyone who has read Jules Verne's classic novel, 20,000 Leagues Under the Sea, or has viewed movies such as Voyage to the Bottom of the Sea, The Abyss, or The Spy Who Loved Me, probably has been inspired by the possibility of living under water. Since the Earth is about $70 \%$ water and humans most likely evolved from the water, it would only seem natural for us to seek shelter 
beneath the surface. However, underwater colonies actually have many of the same, if not more, design challenges as outer space colonies. Intense pressure from water, cold temperatures, minimal light, the production of food, and the disposal of waste are some of the hurdles that design must solve in the sub-marine environment.

Dissolved gases under pressure are indeed a problem in water. In contrast to the decrease in atmospheric pressure with increases in altitude as in the case of the outer space colonies mentioned above, pressure increases with deeper depths under water. The air we breathe at sea level is comprised of $78 \%$ nitrogen, $21 \%$ oxygen, . $94 \%$ argon, and .04\% carbon dioxide and has an atmospheric pressure of 14.7 psi (1 Atmosphere). Since water is heavier than air, it exerts more pressure. According to the National Oceanic and Atmospheric Association (2010):

A one inch column of water 33 feet tall weighs 14.7 pounds. This pressure, resulting from the weight of water is called hydrostatic pressure. So at a depth of 33 feet, a diver experiences atmospheric and hydrostatic pressure equal to twice the amount of atmospheric pressure. We call this 2 ATA, one from the atmosphere and one from the water. This is called absolute pressure. That means our diver is under a pressure of 29.4 pounds per square inch (psi). At 66 feet down a diver is at 3 ATA and experiences a pressure of 44.1 pounds per square inch, and so on.

As a person descends under water, the increased pressure causes more nitrogen and oxygen to be dissolved in the blood. The increased nitrogen pressure causes nitrogen narcosis, which has symptoms of euphoria, sleepiness, instability, and even blacking-out. Narcosis usually occurs around 30 meters (100 feet) under water and requires decompression on the ascent to prevent decompression sickness (DCS), also referred to as "the bends". Decompression can be done inside a chamber in the case of extremely deep, high-pressure exposure, or can be done in a series of "stops" at preset depths during the ascent to the surface to allow the nitrogen to slowly be released from the body. The severity of DCS and subsequent amount of decompression time are directly related to depth and the amount of time spent under water. For example, extended underwater habitation experiments such as the 58-day Tektite I mission in 1969 required more than 19 hours of decompression therapy before the aquanauts were able to safely return to the surface. (Edel, 1971) In the 1960's, divers started to experiment with saturation diving, where the diver is exposed to sufficient duration so that the diver's tissue gases reach equilibrium with the pressure of the underwater environment. Once the diver's tissues reach this equilibrium, the decompression time does not increase with additional time under water.

The first underwater habitat was developed in the early 1960's by aquanaut Jacques Cousteau. Conshelf I, as it became to be known, was eventually constructed 10 meters below the water off the coast of France in the Atlantic Ocean in 1962. Two aquanauts lived in the habitat for seven days and were among the first to breathe a mix of helium and oxygen. Conshelf I was followed by Conshelf II in 1963 in the Red Sea and Conshelf III in 1965 in the Mediterranean, where aquanauts lived at depths down to 30 meters and 100 meters, respectively. (Vorosmari, 1997). Various other underwater living experiments also were conducted in the 1960's and 1970's, including SEALAB off the coast of Bermuda, Tektite (mentioned above) in the US Virgin Islands, Aquarius, Marine Lab, La Chalupa (now Jules' Undersea Lodge), and the Scott Carpenter Space Analog Station. There are also currently several recreational underwater destinations, including the Hilton Maldives Undersea Restaurant in Singapore, Sea World in Florida, and the Red Sea Star Restaurant in Israel. In addition, several projects are in development, including the Hydropolois Hotel in Dubai, the Poseidon Undersea Resort in Fiji, and aquanaut Dennis Chamberland's Atlantica - what is dubbed as the first permanent human underwater colony. Atlantica. With the exception of Atlantica, most of these are all at moderate 
depths between 5-7 meters and thus do not require decompression. Shallower depth colonies, although easier to construct and colonize, may not provide ample protection to a biological pandemic or a cosmic collision. They may still, however, provide an alternative to consuming land, generating power from tides, and spawn new discoveries in marine biology and oceanography. They may also provide fallout shelters for coastal regions exposed to tsunamis and hurricanes.

Deeper colonies around the 30 meter depth are either open to ambient pressure, which means that the interior atmosphere pressure is equal to the surrounding water pressure, or are closed to the sea with air-locked hatches, whereby interior pressure is less than the surrounding water pressure. Open systems are frequently employed in lab settings where divers are submerged for long periods and entering and exiting the lab into the water on a frequent basis. Since the pressure inside the lab is equal to the water pressure, there is no need for decompression each time the diver swims back into the lab. The Aquarius Undersea Laboratory located 62 feet below the surface off the coast of Key Largo, Florida, is an example of an ambient pressure habitat.

The entryway within the wet porch, called the moon pool, remains open as the equivalent air pressure inside prevents water from flowing in. The pressure of the habitat, which is about 47 feet below the surface, is roughly 2.5 times greater than the atmospheric pressure found at sea level. At this depth and pressure, nonsaturated visitors have less than about 80 minutes to visit and return to surface before they risk DCS. However, the mission aquanauts living in Aquarius can stay indefinitely, but undergo 17 hours of decompression that is conducted within Aquarius itself while on the bottom. At the end of decompression, aquanauts exit Aquarius and scuba dive back to the surface. (NOAA, 2010)

The decompression chamber is essentially a "closed' system that maintains sea level pressure. Since the habitat portion of Aquarius is only at 47 feet (14.3 meters), the mix of air used inside is similar to the mix we breathe at sea level. However, colonies at greater depths require mixes of helium and oxygen or mixtures with higher oxygen/lower nitrogen contents (Nitrox) to reduce nitrogen uptake in the body tissue. Helium/oxygen mixtures were used in the Conshelf missions mentioned above.

Closed systems are similar to submarines where the interior air pressure is maintained around 1 ATM. Such systems require heavy construction to withstand the pressure differential and require either pressure shafts or submarines to transport people to the submerged habitats. Unlike ambient systems, air mixtures in closed systems are able to be kept closer to sea-level conditions. The water depth determines the thickness of walls and openings and the types of connections.

In both types of underwater habitats, oxygen must be replenished, carbon dioxide must be removed, temperature must be maintained, fresh water must be supplied, waste must be recycled, and power must be generated. Oxygen can be supplied from pressurized tanks or through the electrolysis of water whereby the oxygen molecules are separated from the hydrogen molecules and carbon dioxide can be removed by scrubbers containing a solution of soda lime. Sea water can be distilled into fresh water via distillation plants that remove salt. Electrical power can be generated from nuclear reactors, steam turbines, diesel engines, or from currents using a tidalturbine. Sunlight can be "siphoned" from the surface using solar tubes that use advanced optics.

In addition to potentially providing protection against disasters, underwater designs might have to be tapped when land becomes scarce. The engineering advancements applied to submarine environments may also spawn new technologies that can be applied to areas prone to 
earthquakes, flooding, hurricanes and tornadoes. After the devastation to Louisiana from Hurricane Katrina in 2006, architects and engineers have been devising new designs for flood management and structures that are capable of residing in water and/or resisting lateral forces from extremely high winds. Other novel concepts have included structures capable of rising above the water via hydraulic columns or structures that actually float such as Naval Architect Giancarlo Zema's "Floating House.” Zema also has designs for cliff-dwellings that rise from the depths of the sea up along steep shoreline cliffs.

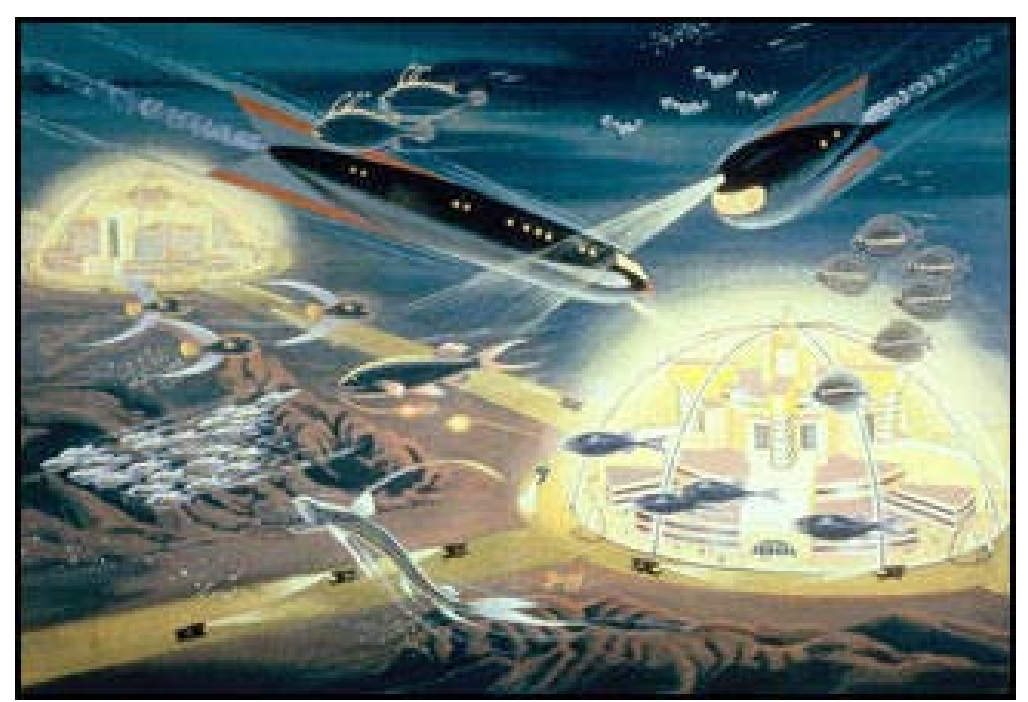

Figure 6: Underwater Colony, Courtesy David Szondy via IF Magazine, Author Unknown

\section{Conclusion}

Our planet is currently facing complex global environmental challenges such as climate change, depletion of natural resources, destruction from natural disasters, pollution, disease, poverty, population growth and threats from extremist terrorist groups. In recent times, many professions - particularly the fields of architecture and engineering - have embraced notions of sustainability in varying capacities by designing products that minimize their carbon footprint. Green buildings, renewable energy technologies, and zero-emission vehicles are becoming more commonplace, and structures capable of withstanding seismic impacts, hurricanes, tornadoes, flooding and terrorist attacks are replacing the antiquated, decrepit structures of the past. Many humans are beginning to look forward, take responsibility for the destruction we have inflicted, and plan for future generations. But are we planning far enough into the future? What will our planet be like one-thousand years from now?...or a million years from now? Are we prepared for events beyond our control such as a cosmic collision, a nuclear holocaust, a biological pandemic, or a complete depletion of natural resources? Are we prepared for the inevitable events that will occur due to the aging of our sun? Do we have a plan to preserve the human race when there is no sun and/or if our planet is subsequently destroyed?

Although these events are millions to billions of years away, humanity needs to start 
planning for them now. Professional fields need to expand in knowledge in order to plan, design and implement projects to respond to such disasters. Due to its visionary and progressive nature, the field of architecture must assume a leadership role in this long-term sustainability mission. As Daniel E. Williams writes in his book, Sustainable Design: Ecology, Architecture and Planning (2007):

\begin{abstract}
The architect - as a generalist - is well suited for this role. Architects help to facilitate multidisciplinary teams that work toward rethinking how things are done and challenging standard practice. The joining of science and design, a mutually beneficial collaboration, offers a new conversation that is holistic and inclusive. Bringing environmental fields together with government and the public and illustrating the power of design as a tool in helping to achieve a sustainable future is a compelling challenge and a call to bold action. This challenge requires that the profession of architecture expand its reach in knowledge and scope, and to not only require multiple disciplines at the table but to learn these disciplines well enough to understand and address the challenges facing us. (p. 256).
\end{abstract}

Indeed, the architecture of the $21^{\text {st }}$ Century must continue to gain expertise in the sciences and humanities. The architect must not only be able to design, but must also be able to engineer, plan, and implement the vision. Such expertise will enable the architect to design sustainable solutions in response to the inevitable cataclysmic disasters facing our planet, for one day, the human race may have no choice but to live in outer space, on a distant moon or planet, under the water, under the ground, or in self-contained biospheres.

As humans, we do have limitations - we can only do our best with the knowledge we have in the present to attempt to sustain our planet in the future. Some of these events may simply be too complex to solve and we might have to accept an inexorable termination of the human race as our destiny. However, such a thought might be too grim for some to come to terms with. History has also demonstrated that the human race, as an intelligent species, is bold and have accomplished major feats; some 5-8 million years ago, we walked upright; we survived several periods of deep freezing, with last glacial age around 16,000 to 12,000 years ago; we developed a means of communication and learned to live from the land; we constructed massive pyramids and elaborate temples roughly 4500 to 2500 years ago; we have witnessed the rise and fall of empires, kingdoms, religions, governments and cities; we have seen the progression of industry and technology from the first telegraph, automobile and airplane to high-speed computer networks, hybrid vehicles, and sophisticated spacecraft capable of landing on nearby planets; we have seen advances in medical technology that our ancestors could only dream of. With the proper foresight, it is possible that we can sustain our existence against extreme alterations and/or the complete disintegration of our planet. 


\section{References}

1. Astronomy Encyclopedia. (2002). New York: Oxford University Press.

2. Boeing. The International Space Station. Retrieved May 2010 from, http://www.boeing.com/defense-space/space/spacestation/.

3. Center for Disease Control and Prevention. Bioterrorism Overview. Retrieved May 2010 from, http://emergency.cdc.gov/bioterrorism/overview.asp.

4. Danford, Gary Scott.(1994). Exerpt from Spring 1994 Syllabus. Environmental Behavior and Design: The Nike Jesus Project. AP 205, University at Buffalo, The State University of New York.

5. Dickinson, Terrance. (1992).The Universe and Beyond. ( $3^{\text {rd }}$ Edition). Altona, Manitoba: Camden House.

6. Dixon, Dougal. (1996). The Earth, It’s Wonders, It's Secrets: Natural Disasters. London: The Readers Digest Association.

7. Dubinski, John. (2006). The Great Milky Way Andromeda Collision. Sky \& Telescope, October 2006.

8. Earth Pledge \& Katrin Scholz-Barth. (2005). From Grey to Green: Environmental Benefits of Green Roofs. In Green Roofs: Ecological Design and Construction. Atglen, PA: Schiffer Publishing.

9. Ebert, Charles H.V. (1993). Disasters: Violence of Nature, Threats by Man. Dubuque, Iowa: Kendall/Hunt.

10. Edel, PO (1971, June). Delineation of Emergency Surface Decompression \& Treatment Procedures for Project Tektite Aquanauts. Aerospace Medicine. 42(6) 616-621.

11. Hellmund, Paul Cawood \& Daniel Somers Smith. (2006). Designing Greenways: Sustainable Landscapes for Nature and People. Washington, DC: Island Press.

12. Lifeboat Foundation, a. Existential Risk Programs. Retrieved May 2010, from http://lifeboat.com/ex/programs

13. Lifeboat Foundation, b. Bioshield. Retrieved May 2010, from http://lifeboat.com/ex/bio.shield

14. NASA (National Aeronautics and Space Administration). Space Settlement Basics. Retrieved May 2010 from, http://settlement.arc.nasa.gov/Basics/wwwwh.html.

15. NASA. Near Earth Object Program (a). NEO Basics. Retrieved May 2010, from 
http://neo.jpl.nasa.gov/neo/.

16. NASA. Near Earth Object Program (b). Close Approaches. Retrieved May 2010, from http://neo.jpl.nasa.gov/ca/.

17. National Oceanic and Atmospheric Administration. Aquarius. Retrieved May 2010 from, http:www.uncw.edu/aquarius/about/overview.htm.

18. Scaled Composites. SpaceshipOne. Retrieved May 2010 from, http://www.scaled.com/projects/tierone/

19. Schmidt, Stanley \& Robert Zubrin (editors). (1996). Islands in the Sky: Bold New Ideas for Colonizing Space. New York \& Canada: John Wiley \& Sons.

20. United States Department of Agriculture, National Resource Conservation Service. Natural Resources Inventory. Retrieved April 2009 from http://www.nrcs.usda.gov.

21. Vorosmarti, James. (1997, Winter). A Very Short History of Saturation Diving. Historical Diving Times, Issue 20.

22. White, Matthew. Historical Atlas of the Twentieth Century. Deaths by Mass Unpleasantness.

23. Retrieved May 2010 from, http://users.erols.com/mwhite28/warstat8.htm.

24. Williams, Daniel E. (2007). Sustainable Design: Ecology, Architecture and Planning. New Jersey: John Wiley \& Sons.

25. World Almanac and Book of Facts 2010. New York: InfoBase Publishing.

26. Worldwatch Institute. (2006). Vital Signs: The trends that are Shaping our Future. New York: WW Norton \& Company.

27. Wright, Richard T. \& Bernard J. Nebel. Environmental Science: Toward a Sustainable Future. ( ${ }^{\text {th }}$ Edition). New Jersey: Pearson Education.

\section{Sources for Illustrations}

Figure 1: Toroidal Space Colony, Exterior View. Courtesy: NASA, Ames Research Center Figure 2: Toroidal Space Colony, Interior View. Courtesy: NASA, Ames Research Center Figure 3: Cylindrical Space Colony, Courtesy: NASA, Ames Research Center Figure 4: Bernal Sphere Space Colony, Courtesy: NASA, Ames Research Center Figure 5: International Space Station, Courtesy: NASA Illustration via Boeing Figure 6: Underwater Colony, Courtesy David Szondy via IF Magazine, Author Unknown 
